This item was submitted to Loughborough's Research Repository by the author.

Items in Figshare are protected by copyright, with all rights reserved, unless otherwise indicated.

\title{
Food, feeding and the material everyday geographies of infants: possibilities and potentials
}

\section{PLEASE CITE THE PUBLISHED VERSION}

http://dx.doi.org/10.1080/14649365.2016.1193889

\section{PUBLISHER}

Routledge (Taylor \& Francis Group)

VERSION

AM (Accepted Manuscript)

\section{PUBLISHER STATEMENT}

This work is made available according to the conditions of the Creative Commons Attribution-NonCommercialNoDerivatives 4.0 International (CC BY-NC-ND 4.0) licence. Full details of this licence are available at: https://creativecommons.org/licenses/by-nc-nd/4.0/

\section{LICENCE}

CC BY-NC-ND 4.0

\section{REPOSITORY RECORD}

Holt, Louise. 2016. "Food, Feeding and the Material Everyday Geographies of Infants: Possibilities and Potentials". Loughborough University. https://hdl.handle.net/2134/20390. 
Food, feeding and the material geographies of infants

Food, feeding and the material everyday geographies of infants: possibilities and potentials

Louise Holt

Loughborough University

Department of Geography

Loughborough

LE11 3TU

UK 
Food, feeding and the material geographies of infants

\begin{abstract}
This paper forges an agenda for researching geographies of infants. Scholars have tended to overlook the everyday geographies of very young children. However, outside of geography, infancy is seen as a specifically dynamic period of life, and is subject to sustained research and policy intervention. In particular, early childhood is viewed as a key point in which to intervene to transform enduring, interconnected, societal, educational, and health based inequalities (Department of Health and Department for Education, 2013; US Early Head Start Act, 2007). Food and feeding are seen as critical both to the health of infants now and of the children and adults they become (NHS Start 4 Life, 2010). However, much policy and research undertheorises the importance of socio-spatial contexts and the subjectivity/agency of infants. There is, then, an urgent need for geographers to put infants onto the agenda, to inform and challenge these dominant accounts. Researching with infants necessitates not just critiquing modern, liberal notions of an autonomous subject/agent, but developing a new way of understanding subjectivity and agency. Drawing upon Lupton's (2013) notion of infant-carer interembodiment, I suggest a way forward with reference to the material geographies of infant feeding.
\end{abstract}

\title{
Key words:
}


Food, feeding and the material geographies of infants

Infants; geographies of children, youth and families; babies; subject/agent; infant feeding; health; socio-spatial inequalities; food; materiality

\section{Introduction}

The idea of exploring infant geographies emerged as a result of being asked to give a presentation to an audience of geographers of children and youth shortly following my first maternity leave. I wondered what I could write about, given I had spent the best part of a year in an overwhelming and all-consuming baby focused time-space. Before I started my maternity leave my husband and I jokingly labelled it my sabbatical. Although I realized that I would have plenty to do, in my naiveté I was also intending to catch up with all my reading. I had envisaged that in the early months, I would have lots of time as the baby slept during the day - and when I was not catching up with my own sleep I would read articles and books - both academic and instructions about how to be a parent. How my baby wonderfully intruded her own self on my plans. At the same time I was destabilised in my own sense of bounded self-identity or subjectivity by the physical and emotional co-dependency of myself and my baby, as others have been (Longhurst, 2008; Tahhan, 2013). My baby and I had been intimately interconnected as she grew inside my body as a foetus, connected by the placenta (Colls and Fannin, 2013). This material and psychic interdependency was continued after birth by breastfeeding and caring for her needs. She seemed so vulnerable and her life precarious (Lupton, 2014). Importantly, however, the psychic and material interdependency was not just between myself and my baby, but was also connected to a variety of human and non-human 'others'. Notably the baby's dad (my husband), grandparents, a wider extended family, the food I ate, midwives, health visitors, weighing scales, the garden, the sea, and so on. 
At the same time as I was so consumed and destabilised by being a new mother, I became intrigued by why had I read so few geographical, or social, studies that really, seriously, included babies or very young children as competent agents. I begin to approach this question in this paper. The relative absence of infants as research partners mirrors the previous neglect of children and youth in geography and the social sciences. I also begin to question these issues in an earlier paper (Holt, 2013). The earlier paper finds immanent baby geographies in Judith Butler's work on the Psychic Life of Power. This paper reflects further upon these concerns to explore more specifically the potentialities of infant geographies within existing geographical and sociological literature. I argue that whereas existing research is emerging that figures infants as recipients of care and increasingly explores what parents and other carers do in relation to subjectifying very young children, the effect of these practices on (and of) the emerging embodied subjectivity/agency ${ }^{\mathrm{i}}$ of infants has been underexplored. In this paper, then, I put more flesh on the bones of exploring how:

“The specific contexts of infants' emergence are of particular interest to exploring the nature of subjection, how enduring inequalities are reproduced via embodied identities, and how social transformation could proceed" (Holt, 2013, p. 658).

In particular, I suggest that Lupton's (2013) concept of interembodiment is a useful starting point for exploring the intersubjective, interdependent subjectivity/agency of infants with their carers. I argue, however, that there is a need to more fully explore how these embodied, material, subjectivities/agencies develop within specific sociospatial and economic contexts, along with examining interembodiment with a range of 


\section{Food, feeding and the material geographies of infants}

people and things. Arguably, these contexts become embodied within material porous, dynamic infant corporealities, via (among other things) different feeding practices. In the final section I reflect upon how this could be taken forward in substantive geographies of infant feeding.

The paper has three main sections. In the next section, I discuss why infants as agents are largely absent from geography and why this absence matters. In the second section, I reflect upon the potentials for infant geographies emerging within feminist geographies of parenting and child caring. In third section, I identify an agenda for exploring infant-carer material and psychic interdependent subjectivity/agency, drawing upon Lupton's (2013) concept of 'interembodiment'. I argue the need for exploring material, tangible, interembodiments in socio-spatially shifting contexts, and interembodiments with a range of people and things. This is crucial since infancy is viewed as a particular moment in the development of human beings in which sociospatial inequalities are (re)produced and have the potential to be challenged, as infancy is such a dynamic period of growth and change. I suggest that more attention needs to be paid to the specific, interdependent, subjectivity/agency of infants within this interembodiment along with the ways in which interembodiments shifts in different socio-spatial contexts. I suggest three potential, interconnected, foci for developing geographies of infants: parent/carer-infant geographies in specific spaces ('public', 'private', 'institutional'), subject(ific)ation within infant-other emotional attachment in different spatial contexts (Holt, 2013); and, the material incorporation of (class) habitus in developing infant bodies via different feeding practices. The third potential avenue of interest is illustrated more fully in the last section, which examines material incorporation of socio-economic inequalities into infants' 
Food, feeding and the material geographies of infants

developing bodies via feeding practices, which have interconnected psychic (Frampton, 2004) and corporeal elements, drawing upon Bourdieu (1984) and Bennett (2009). I conclude by outlining the importance of working towards critical geographies of infants, to challenge dominant accounts of infancy emerging from child development and attachment theory, as indeed critical geographers have challenged psychoanalysis (Bondi, 2014).

Why are infants as agents largely absent from geography, and does this matter?

The emergence of the sub/interdisciplinary field of geographies of children and youth has led to a significant growth in awareness and scholarship about the spaces and spatiality of young people within geography (for recent reviews see Holloway, 2014; Holloway \& Pimlott-Wilson, 2011; Jeffrey, 2010, 2012, 2013; Skelton, 2009, 2015). However, to date, the sub-discipline, geography and, indeed, the wider social sciences (Brownlie \& Leith, 2011; Lupton, 2013b) have tended to neglect the experiences of infants and very young children. The relative absence of very young children as research participants in geographies and social studies of children and youth is tied to the focus of those in the 'middle years of childhood'. Overcoming the tendency to neglect this group has been a pivotal element of the social studies of childhood (James, Jenks, \& Prout, 1998). Accounts of youth have also continued apace (Evans, 2008). A very small number of studies have attempted to engage with young children as agents (Gallacher, 2005; Harker, 2005; Hancock \& Gillen, 2007; Horton \& Kraftl, 2010). I am aware of only one recent study which specifically seeks to explore the geographies of infants as agents (de Campos Tebet, 2015). In this paper I loosely define infants as children under two years of age, following Stern (2006). However, 
Food, feeding and the material geographies of infants

of course, the meaning of infancy is socio-spatially specific and shifting. Infancy is generally viewed as earliest childhood, a period of rapid growth and development, when people change from being a new born baby to a toddler able in most cases to walk and talk. It is this very dynamic bodily growth and enhancing of capacities that is interesting to geographers. Infants challenge children's geographers to re-engage with the changing bodily growth and development of children, and their changing capacities. Infants express agency, certainly, but the way they express this agency is intimately bound with the responses of others; younger infants are pre-vocal, although of course not pre-social, and present challenges to geographers in relation to how we think of children's agency. Also, infant bodies and psyches are materially forged at this time in ways which endure and are carried forward into adult selves (Pile, 1996; Thomas, 2014). In psychology, child development, education and health literature, infancy is viewed as a particular moment to intervene in a host of interconnected socio-spatial and socio-economic inequalities.

The recasting of children as agents has been central to the emergence of geographical and social scholarship about young people (Holloway \& Valentine, 2000; Holt, 2011; Hopkins, 2013; James et al., 1998; Kraftl, Horton, \&Tucker, 2012). Arguably, however, the centrality of seeking children's agency within geographical and social studies of childhood has precluded a serious engagement with infants ${ }^{\mathrm{ii}}$; they do not express the kinds of independent agency which often underpin the research approaches adopted in this inter/sub-discipline - implicitly if not explicitly. It is impossible to 'listen' to 'infants' voices in a straightforward manner. Perhaps infants would not respond well to the participatory, child-centred methods which have been 
Food, feeding and the material geographies of infants

central to other areas of children's geographies (although see de Campos Tebet, 2015). In relation to toddlers, Gallacher (2005, p. 243) claims that:

“Early childhood has been somewhat neglected, perhaps due to 'our' general underestimation of the abilities and social competence of young children and the perceived methodological difficulties in engaging with them"

This argument interestingly mirrors the justifications given for the development of new social studies of childhood (James et al, 1998). Although agreeing with Gallacher (2005) overall, I would further argue that, in order to work with very young children as agents, more needs to be done to unpick the way agency has been understood in geographies of children and youth and in the discipline more broadly. Recent accounts have questioned the nature, and suggested a need for more explicit conceptualisation, of the agency of children and youth (e.g. Blazek, 2013; Gallacher \& M. Gallagher, 2008; Horton \& Kraftl, 2006; Kraftl, 2013; Vanderbeck, 2008) and substantive approaches to researching with children and young people within more critical frameworks have been explored (e.g. Bartos, 2013; Rautio, 2013; Woodyer, 2008). However, pragmatically, in our endeavours to 'listen to the voices' of children, and emphasise the independent capacities and capabilities of children and young people, by contrast to common-sense approaches of young people as having limited agency, geographers of children and youth have often tended to uncritically adopt liberal notions of the agent, which emphasise agency as independent and autonomous, and also somewhat disembodied (see Ruddick, 2007). 


\section{Food, feeding and the material geographies of infants}

If infants are to be included in geographical research in ways which take seriously their agency, an acceptance is required that infants are clearly not the same as adults. The specific difference and corporeal growth and development of children has been somewhat side-lined as an issue in children's geographies, wherein scholars have preferred to focus on the capacities that children have, although this has not been without debate (Jones, 2001). Similarly questions of childhood development, which continue to underpin much social policy towards children, have been neglected, as geographers have jettisoned engagement with child development theory. Child development theory is often viewed as neglecting the socio-spatial specificities of child development and side-lining the everyday social and cultural geographies of children (see Prout, 2005; Holloway, 2014, for critique). However, infants, with their very different capacities and bodies force attention to the embodiment (Aitken, 2001;

Colls and Hörschelmann, 2009; Prout, 2000) and development and growth of children. Indeed, it is timely to re-engage with theories of child development which influence policy and practice, since these theories have often changed in dialogue with critical geographies and social studies of young people (Jenks, 2004; Maynard and Thomas, 2014).

Geographers of children and youth have created a sub/interdisciplinary field around exploring the experiences young people, while simultaneously acknowledging and emphasising the indeterminacy and difficulties of fully defining what a child is. Similarly, I argue for examining the experiences of infants and very young children whilst working with the fluidity of these categories. Like childhood, the boundary between infancy and the rest of childhood is not fixed or given. Infancy must be seen as an embodied socio-spatial construct, and so the exact period of infancy is socio- 


\section{Food, feeding and the material geographies of infants}

spatially specific. Infancy is, however, tied to a specific corporeality, which is interesting for geographers and other social scientists. Infancy is typified by rapid growth, development and change as the child moves from being a pre-vocal (although not pre-social) baby, dependent on others for almost every physical and emotional need, to a toddler generally (although not always) able to talk to some degree, walk, and so on. It clearly can be argued that infants and babies are agents, however, it is also evident that babies do not demonstrate independent, sovereign agency. This, and infants' specific dependency (Keller, 2007) is what is so interesting and challenging to geographers. Infants provoke geographers of children and youth to think differently about agency and development, since infants do not express the kinds of independent agency so often required in participatory research. Infants force geographers to confront that children are not the same as adults, and to think again about processes of development and growth within children's geographies (see also Holloway, 2014), which have been side-lined in the interests of focusing on children's agency. An infant is not the same as an adult, although his/her growth and development at any given stage cannot be equated unproblematically with her/his agency nor can the level of knowledge or development be directly attributed to his/her chronological age. At the same time, since psychoanalytical accounts posit infancy as important in forging adult subjectivities, focusing on infancy can help to critically assess and explore ways of understanding agency as always intersubjective and interdependent. Our infancies and their 'necessary dependencies' (Butler, 2004) are always present in our adult selves. Also intriguing is the interconnected material, bodily process of growth and change, and the ways in which material infant bodies are produced in specific ways in particular contexts. This materiality remains present in adult bodies. The food ingested in childhood has a formative effect on bodies; infants' social origins can 


\section{Food, feeding and the material geographies of infants}

become indelibly marked in their bodies through food consumed, influencing both the materiality of their bodies (Huërou-Luron, Blat, \& Boudry, 2010) and possibly future tastes and preferences (Robinson, Ntani, Simmonds, Syddall, Dennison, Sayer, Barker, \& Cooper, 2013). Therefore, infants are often seen as adults' becomings, and this provides specific insight and interest into how to change and transform inequalities in society. However, the here and now geographies of infancy are of importance and interest to geographers, as those of children and youth have been (Uprichard, 2008).

Engaging with infants necessitates a fuller deconstruction of the notions of agency adopted and a reconfiguring of how agency can be understood in light of this challenge. Our research practices need to engage fully with the idea that all agents only become through intersubjective relations of physical and emotional interdependence in space (see for instance Butler, 2004; Holt, 2013). The very agenda of listening to the voices and experiences of young people and emphasising their agency, which is so central to geographies of children and youth, seems somewhat at odds with post-structural endeavours to deconstruct modern conceptions of 'the agent' from a variety of perspectives. This is problematic since these modern figurations of agency have served to marginalize children, as Ruddick (2007) forcefully points out. Although post-structuralist accounts can assist in deconstructing and problematizing ideas of agency, it is arguably politically and indeed conceptually, problematic to jettison any idea of a specifically human agency (see also Cresswell, 2012). Nonetheless, it is important to consider how to take account in our methodologies of the way that agency is always already subjected, indeed, emerges through subjection (Butler, 1997). Therefore dynamic 'structures' 


\section{Food, feeding and the material geographies of infants}

are embodied within subject/agents, as a condition of their emergence, and thus agents are never sovereign, independent, or autonomous and cannot survey 'from above' all the conditions, limitations and potentialities of their existence. Although agency, then, cannot be known outwith subjectiving power, some part of agency arguably emerges from somewhere beyond this subjectiving power. Implicitly, Butler sites this agency within the sub/beyond conscious, raising the importance of earliest childhood, as further discussed in Holt (2013).

The relative absence of infants within geography and indeed critical social science accounts is particularly problematic given the importance placed on the pre-school age group in theories of child development, critical accounts of social reproduction and psychoanalytical approaches. Infanthood is viewed as the pivotal period in which an individual's capacity to learn is largely established (Keating, 2010), classed dispositions embodied (Bourdieu \& Thompson, 1991) and personality, mental (ill)health and wellbeing and/or anxieties and neuroses laid down (Zeanah, Gunnar, McCall, Kreppner, \& Fox, 2011; Thomas, 2014). A substantial body of research explores earliest childhood and government policies increasingly intervene in this phase of life (e.g. the UK Giving all Children a Healthy Start in Life, Department of Health (DH) \& Department for Education (DfE), 2013; US Early Head Start Act, 2007). There is an intense governmentality of early childhood (N. Rose, 1990). As a result of the limited engagement from geographers and other critical social scientists (although see Brownlie \& Leith, 2011; Gottlieb, 2000; Lupton, 2013), very early childhood remains largely the domain of child development psychologists, psychoanalysts and attachment theorists, particularly, as Moss and Petrie (2002) 
Food, feeding and the material geographies of infants

argue, within the Anglophone countries of the Global North (for exception see Keller, 2013; Olsson, 2010).

Popular books aimed at helping new parents of infants are seeped within 'normalised' notions of both childhood development and infant-parent emotional attachment $(\mathrm{N}$. Rose, 1999). Policy interventions in the earliest years permeate everyday life of parents with small children. Much of the evidence-base of these policies is underpinned by theories of child development and attachment which tend to (re)produce the idea of a normally developing child, the primacy of the mother-infant attachment and underplay socio-spatial variability and context. For instance, discussions of promoting healthy emotional development are often underpinned by John Bowlby and Mary Ainsworth's attachment theories (see Ainsworth, 1969; J. Bowlby, 1973, 1979; 2005; Steele and Steele, 2014; Kraftl, 2013) and Winnicott's, related, concept of the 'good enough mother' (e.g. Winnicott, 1960), which are so pervasive and taken-for-granted they are not always directly referenced.

Midwives and health visitors might provide welcome help to new parents; however, they are also mechanisms of governmentality, intensive surveillance, and control of early parenting by the state, and a specific component of the intensive parenting discussed by Hays (1996); Ferudi (2008); Craig, Powell, and Smyth (2014); Faircloth (2014); and Holloway and Pimlott Wilson (2014) among others. Infants' bodies are constantly weighed and measured and checks are conducted to ensure that infants are within 'normal' ranges. There remains an urgent need to engage in dialogue with the substantial literature about infant development and attachment which predominate in social policy understandings of infancy; a challenge to these scientific knowledges in 
Food, feeding and the material geographies of infants

relation to children more generally was pivotal to the instigation of new social studies of childhood and geographies of children and youth (James et al., 1998; Holloway \& Pimlott-Wilson, 2011).

\section{Immanent geographies of infancy: affective and emotional geographies of parenting/caring, pregnancy and childbirth}

Although infants as agents have not been a central concern for geographers, there are immanent geographies of infants within which this agenda is situated. Infants have been an 'absent presence' within certain sub-disciplines of geography, notably feminist studies and population research. That is the presence of infants has been acknowledged but their perspectives little interrogated. In these sub-disciplines, until recently very young children tend to be present as 'passive recipients of care' (e.g. in feminist research) and/or 'objects of analyses' (e.g. within population geography). Little has been done to take account of the embodied subjectivity/agency of infants. This reflects the position of children more generally within these strands of geographical research until around the 2000s (Holloway \& Valentine, 2000). Conceptualizations of children and childhood have been challenged and transformed within much of geography, including in those sub-disciplines previously critiqued for treating children as objects, such as feminist and population geography (e.g. Holloway \& Pimlott-Wilson 2011; Pimlott-Wilson, 2012; Van Blerk 2008; Valentine, 1997, 2008). However, constructions of infants, specifically, as passive, have been largely uncontested. 


\section{Food, feeding and the material geographies of infants}

The most significant existent geographical literature in which infants feature is broadly feminist studies of child-caring and families. Infants have featured prominently in feminist studies, as they require a great deal of care, which is usually delivered by women - with significant impacts upon their everyday lives, and trajectories in paid careers (A. Gallagher, 2013). A high proportion of feminist studies of caring continue to focus, rather paradoxically, on the 'public' space of non-parental child-care (e.g. Boyer, Reimer, \& Irvine, 2013; Vincent \& Braun, 2013); although of course the nature of privatised commoditised childcare questions the public/private dichotomy, as it is neither a public nor a private space, but a semi-public institutionalised space which only specific individuals - infants and young children, nursery staff and possibly parents or people with parental responsibility, can access.

Despite the insights of these studies, seldom is the subjectivity/agency of infants fully explored, although that of older children might be. Nonetheless, recent feminist studies which interrogate emotional geographies of parenting and 'doing family' with infants (e.g. Aitken, 2000, 2009; Gabb, 2004; Madge \& Connor, 2005, 2006; Luzia, 2010) point to the possibilities of infant geographies. Parents and children have intersubjective relationships based upon reciprocal ties of emotional interdependency - albeit shot through with unequal relations of power between parents and children, between the parents, parents and other family members, and between parents and broader society. Infants, like parents (Madge \& Connor, 2005) are constituted and 'become' subject/agents through these relationships.

These more emotional and affective geographies of parenting have been further developed to explore a variety of caring relationships by Boyer et al. (2013). This 
Food, feeding and the material geographies of infants

research explores the emotional geographies of formal childcare settings, emphasising the emotional nature of the relationships in these spaces. They focus on the positive emotional relationships between children and nursery staff, along with the concept of emotional labour. Indeed, as Boyer et al. (2013) state, much future research could be conducted to explore emotional geographies of various care-settings. However, it would be appropriate to consider more fully the agency of the infants in these settings, following the lead of Gallacher (2005) and Horton and Kraftl (2010).

Studies of the intersubjective, affective, relationships between parents and other carers and children, including infants, begin to highlight the importance of infants as agents. Consider for instance Stuart Aitken's (2000) son Ross, who refused to be pacified in the usual way in the public space of a family gathering, leading to a female relative casting Aitken as having the wrong kind of, masculine, body to care for a child competently. Infant geographies could build upon these accounts by focusing more specifically on the subjectivity/agency of infants within these intersubjective exchanges (see also Aitken and Herman, 1997).

Feminist geographers have become increasingly interested in exploring pre-parenting, birth and breastfeeding; these geographies serve to destabilise dominant, liberal notions of the subject, by emphasising corporeal interdependency, largely from the perspective of the mother. Foetuses and babies are co-present in these studies of pregnancy and birthing (e.g. Longhurst, 2000; 2008), and breastfeeding (e.g. Boyer, 2011, 2012; Longhurst, 2008; Mahon-Daly \& Andrews, 2002; Newell, 2013). The foetus or infant is important, less for its/her/his own subjectivity than as it/he/she emphasises the limits to the bounded subjectivity of the mother, and therefore 
Food, feeding and the material geographies of infants

autonomous subjectivity more generally. For instance, Longhurst (2008, p. 4)

suggests that:

"Pregnant bodies trouble binary thinking. They undergo a bodily process that transgresses the boundaries between inside and outside, same and other, subject and object, and even male and female (when women carry boys)"

The babies and foetuses in Longhurst's fascinating research are imbued with an imminent subjectivity, rather than a subjectivity or agency already realised. As Longhurst (2009) reflects on her experience of researching YouTube birthing videos:

"I found myself wondering how I might feel if I ever happened to meet the child being born and whether I would admit to watching the YouTube video" (p.52).

These studies have inspired Lupton (2013) in developing her idea of interembodiment to conceptualise the complex physical interdependency of mothers in particular, and very young children.

\section{Interembodiment}

Lupton (2013) draws upon Merleau-Ponty and others to develop the concept of interembodiment, or 'skinship' (Tahhan, 2010) to describe the affective, corporeal interconnectedness of (particularly) maternal and infant bodies:

"Through touching-being touched, moving-being moved, feeling-being felt, hearing-being heard, the bodies of the mother and infant come close, or bend to each other, and then spread away from each other. The concept of 'infant' 
Food, feeding and the material geographies of infants

and 'mother' each defines and is inseparable from the other, and each body's 'being-in-the-world' is shaped by the other's" (Lupton, 2013, p. 40).

Interembodiment usefully conceptualises the infant/carer bodies and subjectivities as mutually constituted, intersubjective and interdependent. In a similar vein Tahhan (2013) elucidates the concept of 'touch' as a: “...complexly embodied and sensuous experience..., [which] helps us explore the relations between the emotional and physical sense of touch" (p. 46). This begins to clarify the kind of agency that infants could be viewed as holding, as it is always forged through relationships with others and dependent upon the responses of others. The emergence of the sense (or fiction) of self or a subject/agent occurs within this close interdependent relationship with others. Interembodiment helps to express the particular emotional and physical interdependency of the infant and its carers. As Butler (2004) points out, this dependency is a foundational dependency of subject/agents, which is never left behind.

Although a useful conceptual starting point, I would argue that Lupton (2013) does not substantially get to grips with the specific nature of infants' agency or subjectivity. Instead the discussion swiftly moves on to analyse parents' narratives (see also Brownlie \& Leith, 2011) or discursive representations (Lupton, 2014). The role of the specific subjectivity/agency of the infant is under-explored. Further, the emphasis is on relationships between infants and human 'others', notably, although not exclusively, mothers. However, infants are situated within interembodiments with a host of human and non-human others. The implicit, perhaps unintentional emphasis on the mother-infant relationship, mirrors attachment theory, the continuing power 
Food, feeding and the material geographies of infants

and pervasiveness of which in social policy towards young children is difficult to overstate (Steele and Steele, 2014). It is somewhat surprising that given the importance of attachment theory to social policy and literature pertaining to early childhood development, and some of the similarities in themes with the concept of interembodiment, that Lupton (2013) makes no direct reference to the theory, which perhaps is, nonetheless a shadowy backdrop.

I argue that to fully explore interembodiment, it is necessary to examine the fleshy material reality of infant/carer mind-bodies, how these intersect with, and are pervaded and forged by societal impulses, and connected to a host of human and nonhuman others. This interest is tied to an increasing field of geographies of the body inspired by Longhurst (1997). A geographical perspective could interrogate how these discursive materialities are socio-spatially shifting. The relationship between an infant and its carers is situated in space, performed differently in different places, and the porous boundaries of the interconnected bodies are pervaded and indeed forged and created by a host of social, economic, political and cultural impulses emanating from a variety of scales and origins. The subjectivity/agency of the infant is important in these relationships. Despite many critiques levelled at attachment theories (e.g. see Bessell, 2015; Hollway, 2006), they do emphasise that infants are, from their earliest moments of life, social beings, who seek to provoke specific responses to forge attachment to the adults round them. Music (2010, p. 43) claims that:

“...infants are active partners in interactive exchange, and when things are going well it is often infants who make and break contact. They have few 
Food, feeding and the material geographies of infants

resources at their disposal, but they can look away, avoid contact, gesture and illicit interest...”.

A more explicit engagement with attachment theory could emphasise the child's subjectivity/agency in interembodiment.

At this moment, I can envisage three interconnected, potential foci for developing geographies of infants: parent/carer-infant geographies in specific spaces ('public', 'private', 'institutional'), subject(ific)ation within infant-other emotional attachment in different spatial contexts (Holt, 2013); and, the material incorporation of (class) habitus in developing infant bodies via different feeding practices. This is clearly not an exhaustive list; rather it is a series of suggestions for possible research agendas. At heart these infant geographies tie together recent emotional and socio-cultural geographies of parenting and/or caring for young children with lessons learned from geographies that emphasise the interdependent and emerging agency of young children, to challenge dominant accounts of infant development which do not fully explore the specificity of infants' subjectivity/agency or the socio-spatial contexts of the emergence of the infant. In the remainder of the paper I focus on the final avenue of the material incorporation of socio-spatial contexts in dynamic infant bodies via different feeding practices.

\section{Interembodied geographies of infant feeding: embodying socio-spatial inequalities in dynamic infant corporealities}

Practices of breastfeeding evoke the concept of interembodiment, as Lupton (2013) highlights: 
Food, feeding and the material geographies of infants

"Breastfeeding is an embodied experience that involves parts of the mother's body (the nipple and the breast milk itself) being inserted into the mouth of the infant for lengthy periods, so that their bodies are conjoined in a literal as well as a metaphorical sense" (p.40-14)

Although geographical accounts have emphasised the affectual and emotional aspects of breastfeeding (e.g. Boyer 2012; Longhurst, 2008), they have not fully explored the interembodiment of infants/mothers. Interembodiment has much to offer geographical discussions of breastfeeding, by making these accounts more attune to the interrelationship between the infant and the mother in their experiences of places and spaces. For instance, Boyer (2012) discusses how women breastfeeding in public can feel like 'affect aliens' (Ahmed, 2010, in Boyer 2012: 557). However, interembodiment could give further account of the specific, interconnected and intersubjective agency of infants/carers as they move through and perform space. For instance, some infant/mothers feed quickly, others need an extended latch, making discrete feeding impossible (see Lane, 2014). The intersubjective, or interembodied, relationship between the mother and infant influences the experience of being or not being an 'affect alien' in specific places, and gives an entree into a more sensitive account of infants' intersubjective agency.

At the same time, geographical accounts of breastfeeding have much to contribute to interembodiment, by emphasising that breastfeeding is a set of practices which occur within specific socio-spatial contexts (Boyer, 2011, 2012; Faircloth, 2013). This moves the lens beyond a focus simply on the interembodiment of infants and parents towards the ways infants/parents/carers are situated in, connected to, pervaded by host 
Food, feeding and the material geographies of infants

human and non-human 'others' in specific spaces (Newell, 2013). Indeed, parents' moral and pragmatic decisions about how to feed their infant are tied to their lived experience of different places and their everyday lives (Boyer, 2012). As Pain, Bailey, and Mowl (2001) emphasise, these decisions take place within broader sociospatial contexts and parenting cultures. To date, the focus of geographical research about infant feeding has been on milk feeding, specifically breastfeeding; however, weaning practices, the introduction of solids and the decision of whether to breast feed, and/or when to cease breastfeeding also have important health and sociopsychic implications, which have yet to be explored in geographical and sociological accounts of infant feeding.

Food can be seen as a non-human other in infants' interembodied relationships (Roe, 2006a, b; 2010), although the human/non-human status of breast milk is more equivocal (see also Boyer, 2010). Different infant feeding practices materially create and forge dynamic growing infant bodies and agencies/subjectivities. Bennett (2009, p. 40) emphasises how food becomes human tissue:

“...once ingested, once, that is, food coacts with the hand that places it in one's mouth, with the metabolic agencies of the intestines, pancreas, kidneys .... food can generate new human tissue" .

Bennett (2009) goes on to explore how food has a kind of agency within bodies, in terms of the physiological and neurological outcomes of consuming different foodstuffs, and also the ability of different food compounds to cause cravings in individuals. 
Food, feeding and the material geographies of infants

For infants, the hand (bottle, breast, cup, spoon) that places food/drink into the mouth may belong to someone else and food available (including type of milk) is certainly selected by another. The infant has the ability to refuse the food, and this might change the food offered another time (Carruth, Ziegler, Gordon, \& Barr 2004). In Lupton (2013: 44) mothers' accounts discuss: “infants' potential to manipulate the feeding relationship for their own ends as they grow older, and thus [mothers] view them as acquiring agency and the ability to negotiate". Therefore the specific and changing interembodied subjectivity/agency of infants warrants further analysis within these geographies of infant feeding. Infants' agency is specific and can only be understood in relation to the others with whom s/he connects, and upon whose response s/he is dependent. Although the interembodiment of infants and carers is particularly visceral, all humans are interembodied, interconnected and enacting their agency is dependent upon the response of others (Butler, 2004). Hence examining feeding opens up interembodiment to explore how a range of bodies, both human and non-human intersect and co-act with each other.

These interembodiments occur within specific and differentiated socio-spatial contexts. It is intriguing to consider how different foodstuffs are viewed as more or less desirable, affordable, or appropriate for infants. These differences might be tied to specific gendered moral geographies (see Aitken, 2000; Duncan \& Smith, 2002; Duncan, 2005 Foy-Phillips \& Lloyd-Evans, 2011; Holloway, 1998; McDowell, Ray, Perrons, Fagan, \& Ward, 2006; McDowell, 2006, 2008) or ‘caringscapes' (S. Bowlby, 2012; see also Jupp, 2013). Bourdieu's concept of habitus usefully helps to conceive how 'external realities' forge and create bodies (see for instance, Bourdieu, 1984; 


\section{Food, feeding and the material geographies of infants}

Bourdieu \& Thompson, 1991; see also Holt, 2006; McDowell, 2006, 2008; Reay, 2004). Importantly, Bourdieu does not provide a singular definition of habitus, and habitus has been interpreted heterogeneously by different scholars (see Holt, Bowlby \& Lea, 2013, for further discussion). Reay (2004: 34) suggests: "Bourdieu developed the concept of habitus to demonstrate the ways in which not only is the body in the social world, but also the ways in which the social world is in the body". The focus on habitus emphasizes that bodies are porous and connected to broader social processes. Habitus offers a particular sensitivity to material and socio-economic inequalities. Via feeding, habitus becomes literally, corporeally embodied. Bourdieu (1984: 190) claims that '...the body is the most indisputable materialisation of class taste...'. Class, class faction, along with gendered, racialized, sexualized identities, are incorporated into and create material bodies in specific ways.

Via different feeding practices, bodies can be a mechanism for the (re)production of intergenerational inequalities. The food eaten in childhood forges infant bodies and the materiality of infant bodies remains present in the adults they become (HuërouLuron, Blat, \& Boudry, 2010; Robinson , Ntani, Simmonds, Syddall, Dennison, Sayer, Barker, \& Cooper, 2013). Therefore, understanding infant feeding practices could help to untangle the ways in which infants' bodies and the adult bodies they become are implicated in the (re)production of enduring health inequalities (Graham, 2009). Importantly, understanding the interembodiment of feeding relationships in different socio-spatial contexts should help to unravel: the social contexts of infant feeding practices; the role of the affective relationship between infants/carers/others; how infants' materials bodies and subjectivities are forged in these contexts; and, the role of infants' specific, changing, embodied intersubjectivity/agency. 
Food, feeding and the material geographies of infants

\section{Conclusion}

In this paper I have put more flesh on the bones of an agenda for exploring the geographies of infants and their parents/carers. Although inspired by existing work in geographies of children, youth and families, and feminist geographies, these substantive geographies of infants are distinct in foregrounding the embodied intersubjective subjectivity/agency of infants and carers in their socio-spatial contexts. It is important that geographers explore geographies of infants. As infancy is viewed as crucial to the emergence of the subject/agent, public policy interventions and attempts to intervene in earliest childhoods abound (e.g. DH and DoE, 2013; US Early Head Start Act, 2007). These currently tend to be based on theories of child development and attachment, which, while they provide some insights, generally do not take full account of the social and cultural geographies of infants' emergence. By not reflecting fully on different socio-spatial contexts of infants, these accounts too often inadvertently embody ethnocentric, bourgeois, (dis)ableist and sexist positions, which are then imposed upon a variety of family and caring contexts via wellmeaning public policies. There is, then, an urgent need for social and cultural geographers to bring their critical gaze to bear more fully on this important arena.

I have suggested three possible avenues for exploring infant geographies:

parent/carer-infant geographies in specific spaces ('public', 'private', 'institutional'), subject(ific)ation within infant-other emotional attachment in different spatial contexts (Holt, 2013); and, the material incorporation of (class) habitus in developing infant bodies via different feeding practices. In this paper I more fully reflect upon the final potential avenue to consider how broader socio-spatial inequalities might be 


\section{Food, feeding and the material geographies of infants}

materialised in infants' growing and developing bodies via feeding practices.

Researching with infants in ways that takes account of their specific

subjectivity/agency necessities, not just a destabilisation of liberal notions of agency, which is part of a broader endeavour in human geography, but also creatively rethinking and reimagining subjectivity/agency. The concept of interembodiment developed by Lupton (2013) has provided a useful starting point to consider the psychic, social and material interdependency of infants and those who care for them, and also has a wider applicability beyond exploring infancy in helping to reconfigure agency/subjectivity beyond liberal notions. However, I suggest a need to more fully examine material, corporeal infant subjectivities/agency and consider the differing socio-spatial contexts of interembodiments. One possible way forward is to explore the specific material contexts of infant feeding. Since food becomes bodily matter in a material sense, and particular socio-cultural geographies of attachment are forged through different feeding practices, food and infant feeding offer an insightful lens into the bodily reproduction of socio-spatial inequalities. However, researchers examining these issues must critically reflect on their research practices to avoid becoming or seeming to be part of a broader governmentality of early childhood.

A final reflection is that my concern with infant geographies is clearly framed by my largely positive, although sometimes fraught, interembodiment with my three children, from my reflective perspective. This is connected to my subjectification as a white, relatively wealthy, non-disabled British woman in a heterosexual marriage. The subjectivity/agency of my three children, with their different personalities is also important here. There are clearly many different geographies of infants/carer/other interembodiment to be written. 


\section{References}

Ahmed, S. (2010). Killing joy: Feminism and the history of happiness. Signs, 35(3), $571-594$.

Ainsworth, M. D. (1969). Object relations, dependency, and attachment: A theoretical review of the infant-mother relationship. Child Development, 40(4), 969-1025.

Aitken, S. C. (2000). Fathering and faltering: 'Sorry, but you don't have the necessary accoutrements'. Environment and Planning A, 32(4), 581-598.

Aitken, S. C. (2001). Geographies of young people: The morally contested spaces of identity. London: Routledge.

Aitken, S. C. (2009). The awkward spaces of fathering. Aldershot: Ashgate.

Aitken, S. C., \& Herman, T. (1997). Gender, power and crib geography: Transitional spaces and potential places. Gender, Place and Culture: A Journal of Feminist Geography, 4(1), 63-88.

Bartos, A. E. (2013). Children sensing place. Emotion, Space and Society, 9, 89-98.

Bennett, J. (2009). Vibrant matter: A political ecology of things. Durham NC: Duke University Press.

Bessell, S. (2015). Rights-based research with children: Principles and practice. In R. Evans, \& L. Holt (Eds.), Methodological approaches. Volume 2, in Skelton, T. (editor-in-chief) Geographies of Children and Young People. (Springer Singapore). 
Food, feeding and the material geographies of infants

Blazek, M. (2013). Emotions as practice: Anna Freud's child psychoanalysis and thinking-doing children's emotional geographies. Emotion, Space and Society, 9, 24-32.

Bondi, L. (2014). On Freud's geographies. In P. Kingsbury, \& S. Pile (Eds.), Psychoanalytic geographies (pp. 57-72). Farnham: Ashgate.

Bourdieu, P. (1984). Distinction: A social critique of the judgement of taste. Cambridge MA: Harvard Univ Press.

Bourdieu, P., \& Thompson, J. (1991). Language and symbolic power. Cambridge MA: Harvard Univ Press.

Bowlby, J. (1973). Attachment and loss. vol. 2: Separation: Anxiety and an. New York: Basic Books.

Bowlby, J. (1979). The making and breaking of affectional bonds. London: Tavistock.

Bowlby, J. (2005). A secure base: Clinical applications of attachment theory. London: Routledge.

Bowlby, S. (2012). Recognising the time-space dimensions of care: Caringscapes and carescapes. Environment and Planning-Part A, 44(9), 2101.

Boyer, K. (2010). Of care and commodities: Breast milk and the new politics of mobile biosubstances. Progress in Human Geography, 34(1), 5-20.

Boyer, K. (2011). "The way to break the taboo is to do the taboo thing." Breastfeeding in public and citizen-activism in the UK. Health \& Place, 17(2), 430-437. 
Food, feeding and the material geographies of infants

Boyer, K. (2012). Affect, corporeality and the limits of belonging: Breastfeeding in public in the contemporary UK. Health \& Place, 18(3), 552-560.

Boyer, K., Reimer, S., \& Irvine, L. (2013). The nursery workspace, emotional labour and contested understandings of commoditised childcare in the contemporary UK 1. Social \& Cultural Geography, 14(5), 517-540.

Brownlie, J., \& Leith, V. M. S. (2011). Social bundles: Thinking through the infant body. Childhood, 18(2), 196-210.

Butler, J. (1997). The psychic life of power: Theories in subjection. Stanford, Ca: Stanford University Press.

Butler, J. (2004). Undoing gender. New York: Routledge.

Carruth, B. R., Ziegler, P. J., Gordon, A., \& Barr, S. I. (2004). Prevalence of picky eaters among infants and toddlers and their caregivers' decisions about offering a new food. Journal of the American Dietetic Association, 104, 57-64.

Colls, R., \& Fannin, M. (2013). Placental surfaces and the geographies of bodily interiors. Environment and Planning A, 45(5), 1087-1104.

Colls, R., \& Hörschelmann, K. (2009). Editorial: Geographies of children's and young people's bodies. Children's Geographies, 7(1), 1-6.

Craig, L., Powell, A., \& Smyth, C. (2014). Towards intensive parenting? changes in the composition and determinants of mothers' and fathers' time with children 1992-2006. The British Journal of Sociology, 65(3), 555-79.

Cresswell, T. (2012). Review essay. Nonrepresentational theory and me: Notes of an interested sceptic. Environment and Planning-Part D, 30(1), 96. 
Food, feeding and the material geographies of infants

de Campos Tebet, Gabriela Guarnieri. (2015, January). Geography of babies:

Following babies' movements and networks. Fourth International Conference on Geographies of Children, Youth and Families, San Diego,

Department of Health, \& Department for Education. (2013). Giving all children a healthy start in life. London: The Stationary Office.

Duncan, S. (2005). Mothering, class and rationality. The Sociological Review, 53(1), $50-76$.

Duncan, S., \& Smith, D. (2002). Geographies of family formations: Spatial differences and gender cultures in Britain. Transactions of the Institute of British Geographers, 27(4), 471-493.

Evans, B. (2008). Geographies of youth/young people. Geography Compass, 2(5), 1659-1680.

Faircloth, C. (2013). Militant lactivism?: Attachment parenting and intensive motherhood in the UK and France Berghahn Books.

Faircloth, C. (2014). Intensive parenting and the expansion of parenting. In E. Lee, J. Bristow, C. Faircloth \& J. Macvarish (Eds.), Parenting culture studies (pp. 2550). London: Palgrave Macmillan.

Foy-Phillips, P., \& Lloyd-Evans, S. (2011). Shaping children's mobilities: Expectations of gendered parenting in the English rural idyll. Children's Geographies, 9(3-4), 379-394.

Frampton, E. (2004). Fluid objects: Kleinian psychoanalytic theory and breastfeeding narratives. Australian Feminist Studies, 19(45), 357-368. 
Food, feeding and the material geographies of infants

Furedi, F. (2008). Paranoid parenting: Why ignoring the experts may be best for your child. London: Continuum.

Gabb, J. (2004). 'I could eat my baby to bits'; passion and desire in lesbian motherchildren love. Gender, Place \& Culture, 11(3), 399-415.

Gallacher, L. (2005). 'The terrible twos': Gaining control in the nursery? Children's Geographies, 3(2), 243-264.

Gallacher, L. A., \& Gallagher, M. (2008). Methodological immaturity in childhood research? Childhood, 15(4), 499.

Gallagher, A. (2013). The politics of childcare provisioning: A geographical perspective. Geography Compass, 7(2), 161-171.

Gottlieb, A. (2000). Where have all the babies gone? Toward an anthropology of infants (and their caretakers). Anthropological Quarterly, 73(3), 121-132.

Graham, H. (2009). Understanding health inequalities. Pennsylvania: McGraw-Hill International.

Hancock, R., \& Gillen, J. (2007). Safe places in domestic spaces: Two-year-olds at play in their homes. Children's Geographies, 5(4), 337-351.

Harker, C. (2005). Playing and affective time-spaces. Children's Geographies, 3(1), 47-62.

Hays, S. (1996). The cultural contradictions of motherhood. New Haven, CT: Yale University Press. 
Food, feeding and the material geographies of infants

Holloway, S. L. (1998). Local childcare cultures: Moral geographies of mothering and the social organisation of pre-school education. Gender, Place and Culture: A Journal of Feminist Geography, 5(1), 29-53.

Holloway, S. L. (2014). Changing children's geographies. Children's Geographies, 12(4), 377-392.

Holloway, S. L., \& Pimlott-Wilson, H. (2014). Enriching children, institutionalizing childhood? Geographies of play, extracurricular activities, and parenting in England. Annals of the Association of American Geographers, 104(3), 613-627.

Holloway, S., \& Valentine, G. (2000). Children's geographies and the new social studies of childhood. In S. Holloway, \& G. Valentine (Eds.), Children's geographies: Playing, living, learning (pp. 1-26). London: Routledge.

Hollway, W. (2006). Family figures in 20th-century British 'psy'discourses. Theory \& Psychology, 16(4), 443-464.

Holt, L. (2008). Embodied social capital and geographic perspectives: Performing the habitus. Progress in Human Geography, 32(2), 227.

Holt, L. (2011). Introduction: geographies of children, youth and families: disentangling the socio-spatial contexts of young people across the globalizing world. In Holt, L. (Ed.) Geographies of children, youth and families: An international perspective (p. 1-8) London: Routledge.

Holt, L. (2013). Exploring the emergence of the subject in power: Infant geographies. Environment and Planning D: Society and Space, 31, 645-663. 


\section{Food, feeding and the material geographies of infants}

Holt, L., Bowlby, S., \& Lea, J. (2013). Emotions and the habitus: Young people with socio-emotional differences (re)producing social, emotional and cultural capital in family and leisure space-times. Emotion, Space and Society, 9(1), 33-41.

Hopkins, P. E. (2013). Young people, place and identity. London: Routledge.

Horschelmann, K., \& Van Blerk, L. (2013). Children, youth and the city. London: Routledge.

Horton, J., \& Kraftl, P. (2006). What else? Some more ways of thinking and doing 'Children's geographies'. Children's Geographies, 4(1), 69-95.

Horton, J., \& Kraftl, P. (2010). Tears and laughter at a sure start centre: Preschool geographies, policy contexts. In L. Holt (Ed.), Geographies of children, youth and families: An international perspective (pp. 235-248). London: Routledge.

James, A., Jenks, C., \& Prout, A. (1998). Theorizing childhood. Williston, VT: Teachers College Press.

Jeffrey, C. (2010). Geographies of children and youth I: Eroding maps of life. Progress in Human Geography, 34(4), 496.

Jeffrey, C. (2012). Geographies of children and youth II: Global youth agency. Progress in Human Geography, 36(2), 245-253.

Jeffrey, C. (2013). Geographies of children and youth III: Alchemists of the revolution? Progress in Human Geography, 37(1), 145-152.

Jenks, C. (2004). A sociological approach to childhood development. In P. K. Smith, \& C. H. Hart (Eds.), The handbook of child development (pp. 78-94). Oxford: Blackwell. 
Food, feeding and the material geographies of infants

Jones, O. (2001). 'Before the dark of reason': Some ethical and epistemological considerations on the otherness of children. Ethics, Place \& Environment, 4(2), 173-178.

Jupp, E. (2013). Enacting parenting policy? The hybrid spaces of sure start children's centres. Children's Geographies, 11(2), 173-187.

Keating, D. P. (2010). Nature and nurture in early child development. Cambridge: Cambridge University Press.

Keller, H. (2013). Cultures of infancy. New York, Psychology Press.

Kraftl, P. (2013). Beyond 'voice', beyond 'agency', beyond 'politics'? hybrid childhoods and some critical reflections on children's emotional geographies. Emotion, Space and Society, 9, 13-23.

Kraftl, P., Horton, J., \& Tucker, F. (2012). Critical geographies of childhood and youth: Contemporary policy and practice. Bristol: The Policy Press.

Lane, R. (2014). Healthy discretion? breastfeeding and the mutual maintenance of motherhood and public space. Gender, Place \& Culture, 21(2), 195-210.

Le Huërou-Luron, I., Blat, S., \& Boudry, G. (2010). Breast-v. formula-feeding: Impacts on the digestive tract and immediate and long-term health effects. Nutrition Research Reviews, 23(01), 23-36.

Longhurst, R. (1997). (Dis)embodied geographies. Progress in Human Geography, 21(4), 486.

Longhurst, R. (2000). Corporeographies' of pregnancy: Bikini babes'. Environment and Planning D, 18(4), 453-472. 
Food, feeding and the material geographies of infants

Longhurst, R. (2008). Maternities: Gender, bodies and space. London: Routledge.

Longhurst, R. (2009). YouTube: A new space for birth. Feminist Review, 93(1), 4663.

Lupton, D. (2013). Infant embodiment and interembodiment: A review of sociocultural perspectives. Childhood, 20(1), 37-50.

Lupton, D. (2014). Precious, pure, uncivilised, vulnerable: Infant embodiment in Australian popular media. Children \& Society, 28(5), 341-351.

Luzia, K. (2010). Travelling in your backyard: The unfamiliar places of parenting. Social \& Cultural Geography, 11(4), 359-375.

Madge, C., \& O'Connor, H. (2005). Mothers in the making? exploring liminality in cyber/space. Transactions of the Institute of British Geographers, 30(1), 83-97. Head start act, Public LawU.S.C. 653 (2007).

Madge, C., \& O'Connor, H. (2006). Parenting gone wired: Empowerment of new mothers on the internet? Social \& Cultural Geography, 7(02), 199-220.

Mahon-Daly, P., \& Andrews, G. J. (2002). Liminality and breastfeeding: Women negotiating space and two bodies. Health \& Place, 8(2), 61-76.

Maynard, T., \& Thomas, N. (2014). An introduction to early childhood studies. New York: Sage.

McDowell, L. (2006). Reconfigurations of gender and class relations: Class differences, class condescension and the changing place of class relations. Antipode, 38(4), 825-850. 
Food, feeding and the material geographies of infants

McDowell, L. (2008). The new economy, class condescension and caring labour: Changing formations of class and gender. NORA—Nordic Journal of Feminist and Gender Research, 16(3), 150-165.

McDowell, L., Ward, K., Perrons, D., Ray, K., \& Fagan, C. (2006). Place, class and local circuits of reproduction: Exploring the social geography of middle-class childcare in london. Urban Studies, 43(12), 2163-2182.

Moss, P., \& Petrie, P. (2002). From children's services to children's spaces: Public provision, children and childhood.

Music, G. (2010). Nurturing natures: Attachment and children's emotional, sociocultural and brain development. Psychology Press.

Newell, L. (2013). Disentangling the politics of breastfeeding. Children's Geographies, 11(2), 256-261.

NHS Start 4 Life (2010) http://www.nhs.uk/start4life?gclid=CLnR0KHTo8gCFcNCGQodq0wJLA\&gclsr $\mathrm{c}=\mathrm{ds}$

Olsson, L. M. (2009). Movement and experimentation in young children's learning: Deleuze and guattari in early childhood education Routledge.

Pain, R., Bailey, C., \& Mowl, G. (2001). Infant feeding in north east England: Contested spaces of reproduction. Area, 33(3), 261-272.

Pile, S. (1996). The body and the city: Psychoanalysis, space, and subjectivity. London: Routledge. 
Food, feeding and the material geographies of infants

Pimlott-Wilson, H. (2012). Work-life reconciliation: Including children in the conversation. Geoforum, 43(5), 916-925.

Prout, A. (2000). The body, childhood and society. Basingstoke: Macmillan.

Prout, A. (2005). The future of childhood: Toward the interdisciplinary study of children. New York, NY: Routledge

Rautio, P. (2013). Children who carry stones in their pockets: On autotelic material practices in everyday life. Children's Geographies, 11(4), 394-408.

Reay, D. (2004). 'It's all becoming a habitus': Beyond the habitual use of habitus in educational research. British Journal of Sociology of Education, 25(4), 431-444.

Robinson, S., Ntani, G., Simmonds, S., Syddall, H., Dennison, E., Sayer, A. A., Barker, D., Cooper, C. (2013). Type of milk feeding in infancy and health behaviours in adult life: Findings from the Hertfordshire cohort study. British Journal of Nutrition, 109(06), 1114-1122.

Roe, E. (2010). Ethics and the non-human: The matterings of animal sentience in the meat industry. In B. Anderson, \& P. Harrison (Eds.), Taking place: Nonrepresentational theories and geography (pp. 261-280). Aldershot: Ashgate.

Roe, E. J. (2006). Material connectivity, the immaterial and the aesthetic of eating practices: An argument for how genetically modified foodstuff becomes inedible. Environment and Planning A, 38(3), 465.

Roe, E. J. (2006). Things becoming food and the embodied, material practices of an organic food consumer. Sociologia Ruralis, 46(2), 104-121. 
Food, feeding and the material geographies of infants

Rose, N. (1990). Governing the soul: The shaping of the private self. Taylor \& Frances/Routledge.

Ruddick, S. (2007). At the horizons of the subject: Neo-liberalism, neo-conservatism and the rights of the child part one: From 'knowing' fetus to 'confused' child. Gender, Place and Culture, 14(5), 513-527.

Skelton, T. (2009). Children's geographies/geographies of children: Play, work, mobilities and migration. Geography Compass, 3(4), 1430-1448.

Skelton, T. (Ed.). (2015). Geographies of children and young people. Singapore: Springer.

Steele, H., \& Steele, M. (2014). Attachment disorders: Theory, research, and treatment considerations. Handbook of developmental psychopathology (pp. 357370) Springer.

Stern, D. N. (2006). Interpersonal world of the infant: A view from psychoanalysis and development psychology. London: Basic books.

Tahhan, D. A. (2010). Blurring the boundaries between bodies: Skinship and bodily intimacy in japan. Japanese Studies, 30(2), 215-230.

Tahhan, D. A. (2013). Touching at depth: The potential of feeling and connection. Emotion, Space and Society, 7, 45-53.

Thomas, M. E. (2014). When $1+1$ does not equal 2: Childhood sexuality and Laplanche's enigmatic signifier. In P. Kingsbury, \& S. Pile (Eds.), Psychoanalytic geographies (pp. 199-212). Farnham: Ashgate. 
Food, feeding and the material geographies of infants

Uprichard, E. (2008). Children as 'being and becomings': Children, childhood and temporality. Children \& Society, 22(4), 303-313.

Van Blerk, L. (2008). Poverty, migration and sex work: Youth transitions in Ethiopia. Area, 40(2), 245-253.

Vanderbeck, R. M. (2008). Reaching critical mass? Theory, politics, and the culture of debate in children's geographies. Area, 40(3), 393-400.

Vincent, C., \& Braun, A. (2013). Being 'fun' at work: Emotional labour, class, gender and childcare. British Educational Research Journal, 39(4), 751-768.

Winnicott, D. W. (1960). The theory of the parent-infant relationship. International Journal of Psychoanalysis, 41(6), 585-595.

Woodyer, T. (2008). The body as research tool: Embodied practice and children's geographies. Children's Geographies, 6(4), 349-362.

Zeanah, C. H., Gunnar, M. R., McCall, R. B., Kreppner, J. M., \& Fox, N. A. (2011). VI. Sensitive periods. Monographs of the Society for Research in Child Development, 76(4), 147-162.

\footnotetext{
${ }^{\mathrm{i}}$ Using the term subject/agent is intended to represent how agency emerges within the context of subjection, and therefore it is helpful to consider how agency is formed within the context of subjection, but to suggest that people still have agency, can act as agents. This is specifically important to geographers of children and youth, as young people's agency is often under question. There is, of course, ongoing debate about the usefulness of conceptualising a specifically human agency (Cresswell, 2012; Kraftl, 2013). Like Cresswell (2012) I find it helpful to conceive of a specifically human agency, although not a uniquely human agency. Following Butler (2003) and others, it seems important to understand people's ability to act in the world, to change and challenge aspects of the world and the 'structures' that constrain and enable them: consciously and deliberately, purposefully, although of course people are not fully conscious, all knowing, or rational.

ii The institutional constraints of university ethical procedures have been pointed out as a further potential reason for the relative absence of research that focuses on the subjectivity/agency of infants, by an anonymous reviewer.
} 